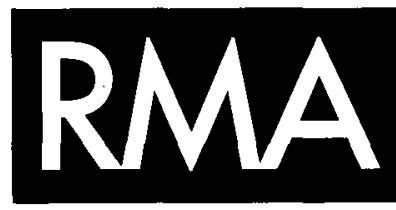

$\overline{\text { ROYAL MUSICAL ASSOCIATION }}$

\title{
Royal Musical
} Association

\section{RESEARCH CHRONICLE}

\section{8: 2005}

Edited by Jonathan P. Wainwright

\section{ARTICLES}

1 Magnus Williamson Liturgical Polyphony in the Pre-Reformation English Parish Church: a Provisional List and Commentary

45 Sally Harper An Elizabethan Tune List from Lleweni Hall, North Wales

99 Karen McAulay Nineteenth-Century Dundonian Flute Manuscripts Found at the Royal Scottish Academy of Music and Drama 